\title{
Circadian rhythm in pain, stiffness, and manual dexterity in rheumatoid arthritis: relation between discomfort and disability
}

\author{
Nicholas Bellamy, Robert B Sothern, Jane Campbell, W Watson Buchanan
}

\begin{abstract}
Fourteen patients with rheumatoid arthritis (RA) self rated their pain and stiffness on separate $10 \mathrm{~cm}$ visual analogue scales and performed bead intubation coordinometry (BIC) on six occasions each day for seven consecutive days. In addition, 14 healthy controls matched for age and sex also performed BIC measurements according to the same schedule. Data were analysed using least squares and cosine vector techniques. Significant circadian rhythms in patients with RA were detected in pain, stiffness, and BIC, and in controls in BIC. Pain was least in patients with RA at 1700 and stiffness at 1724 . Peak BIC performance occurred almost simultaneously in RA (1544) and control (1528) subjects and for subjects with $R A$ occurred within the $95 \%$ confidence interval of least pain and stiffness. These data suggest that the inferior performance of subjects with RA may be an accentuation of the normal physiological variation seen in healthy controls, but may be modulated by the patient's level of pain or stiffness, or both.
\end{abstract}

In recent years a number of investigators have reported circadian variation in clinical ${ }^{1-3}$ and laboratory ${ }^{4-6}$ variables in patients with inflammatory arthritis. In general, these investigators used traditional statistics. For some years, however, statistical techniques based on least squares and cosine vector analysis, which permit the use of real time data, have been successfully used by chronobiologists in mapping the absolute and relative timing of different biological rhythms. ${ }^{78}$ In this study we used these techniques to map the relation between the rhythms of pain, stiffness, and disability in patients with rheumatoid arthritis (RA). We also compared the manual dexterity (as measured by bead intubation coordinometry-BIC) of patients with RA and healthy controls. The purpose of the study was to examine whether such techniques could be successfully used to define the absolute timing of three different biological rhythms and the relativity of one to another, and to conduct a preliminary assessment of BIC as an outcome measure for RA clinical trials.

\section{Materials and methods}

The quasi-experimental study compared repeated measures in two groups-one of 14 patients with RA and the other of 14 healthy controls matched for age and sex. The patients with RA (nine female, five male) had a mean age of 51 years (range 33-65) and mean disease duration of nine years (range 1-17). All patients were in a steady state. The controls (nine female, five male) had a mean age of 51 years (range 34-69). All patients with RA were symptomatic and fulfilled criteria for classic or definite disease. All were taking antirheumatic drugs at the time of study and some were using concomitant supplementary analgesia with acetaminophen. These consecutive consenting patients were maintained on the same drug regimen throughout the study. Control subjects were matched for sex and for age within four years. They were recruited from among hospital staff and were eligible if they were clinically free from musculoskeletal and neurological disease and were not taking drugs for any other condition at the time of study. Each patient with RA was interviewed and examined and their competence and ability to complete pain and stiffness questionnaires verified. In addition, each patient and each control was also instructed and examined on the use of the BIC instrument. Thereafter, each patient was given a questionnaire consisting of two questions: $(a)$ How much pain are you currently experiencing? and $(b)$ How much stiffness are you currently experiencing? Responses for pain and stiffness were separately scaled on $10 \mathrm{~cm}$ horizontal visual analogue scales with terminal descriptors no pain (or stiffness), most severe pain (or stiffness) I have experienced. BIC measurements were self administered. Patients were shown where they should record the real time at which the observation was made and their BIC score. Control subjects only recorded real time and BIC score. The assessments of pain, stiffness, and BIC in patients and BIC in healthy controls were repeated six times a day (at wake up, 1000,1400,1800, 2200, and bedtime) on nine consecutive days. Only data from the last seven days were used in the analysis.

The coordinometer consisted of a shallow circular aluminium receptacle with a flat base $(11.5 \mathrm{~cm})$ and vertical side $(4.0 \mathrm{~cm})$. The top was closed by a Perspex lid, carrying at its centre, a hollow vertical $(8 \mathrm{~cm})$ stainless steel tube. The calibre of the tube was such that it would only accept a series of sandblasted stainless steel precision beads $(0.65 \times 0.48 \mathrm{~cm})$ when they were presented with their long axis exactly corresponding with the axis of the tube. Twenty five such beads were placed in a shallow plastic bowl to one side (determined by hand dominance) of the coordinometer, while a precision stopwatch was placed on the other side at a distance comfortable to the patient. 
Figure 1 Coordinometer.

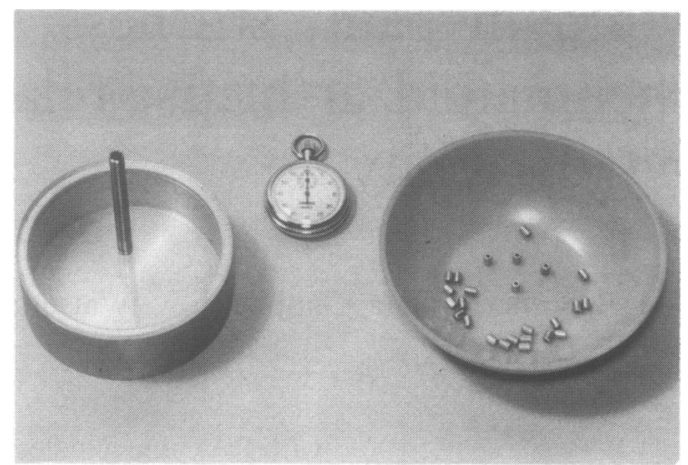

The test started with the patient's dominant hand holding the first bead while the nondominant hand was on the stop watch. Simultaneously, the watch was started and bead intubation commenced. Thereafter, the beads

Table 1 Glossary of terms*

\begin{tabular}{|c|c|}
\hline Acrophase $(\phi)$ & $\begin{array}{l}\text { Peak of fitted cosine indicating highest point in a rhythm and } \\
\text { referenced to: }(a) \text { clock hour and date }\left(00^{\circ} \text { or light onset for } 24 \mathrm{~h} \text {, }\right. \\
22 \mathrm{Dec} \text { for one year; symbol }=\phi) \text {; or }(\mathrm{b}) \text { a distinct point on } \\
\text { synchronising schedule }(\text { for example, lights on, meal time, treatment } \\
\text { time; symbol }=\phi) \text {; or }(c) \text { acrophase of another rhythm (for example, } \\
\text { body temperature or urinary potassium; symbol }=\Phi) \text {. Units used are } \\
\text { either clock hour and minute, calendar date, or negative degrees, } \\
\text { indicating a lag from reference point (where } 360^{\circ}=\text { period fitted; for } \\
\text { example, } 360^{\circ}=24 \mathrm{~h}, 15^{\circ}=1 \mathrm{~h} \text { ) }\end{array}$ \\
\hline Amplitude (A) & $\begin{array}{l}\text { One half the difference between highest and lowest value of a } \\
\text { mathematical model used to describe a rhythm-for example, the } \\
\text { difference between mesor and maximum or minimum of fitted cosine. }\end{array}$ \\
\hline Bathyphase (b $\phi)$ & $\begin{array}{l}\text { Trough of fitted cosine indicating lowest point in a rhythm (see } \\
\text { acrophase). In relation to a single fitted cosine, acrophase and } \\
\text { bathyphase differ by precisely } 180^{\circ}\end{array}$ \\
\hline Chronobiology & $\begin{array}{l}\text { Science investigating and objectively quantifying biological time } \\
\text { structure }\end{array}$ \\
\hline Chronogram & Display of data as a function of time \\
\hline Circadian & $\begin{array}{l}\text { About a day; a biological variation with a frequency of one cycle in } \\
24 \pm 4 \text { hours }\end{array}$ \\
\hline Circaseptan & $\begin{array}{l}\text { About seven days; a biological variation with a frequency of one cycle in } \\
7 \pm 2 \text { days }\end{array}$ \\
\hline Cosinor & $\begin{array}{l}\text { Statistical summary (and optional circular display) of rhythm } \\
\text { characteristics (mesor, amplitude, acrophase) for a single biological } \\
\text { time series (single cosinor) or for three or more in a population } \\
\text { (population mean cosinor). From the words cosine and vector. The } \\
\text { cosine function used is } g(t)=M+A \cos ((2 \pi / t)+\phi)+e(t)\end{array}$ \\
\hline Least squares method & $\begin{array}{l}\text { Computational procedure of fitting a cosine model to time series of data } \\
\text { by least squares method of minimising the residual sum of squares in } \\
\text { order to assess rhythm characteristics of } M, A \text {, and } \phi\end{array}$ \\
\hline Mesor $(\boldsymbol{M})$ & $\begin{array}{l}\text { Rhythm adjusted average, the value midway between the highest and } \\
\text { lowest value of a rhythm defined by a mathematical model-for } \\
\text { example, a cosine }\end{array}$ \\
\hline
\end{tabular}

*This glossary was prepared by $\mathbf{R}$ Sothern (May 1987). For additional and more detailed chronobiological terms see ref 10 . were inserted as fast as possible, one by one, into the tube. Immediately after the insertion of the last bead the non-dominant hand stopped the watch. Patients were instructed that the beads should be picked up one at a time, and if a bead was dropped on the table or the floor this invalidated the test and necessitated starting again. The BIC instrument used in this study was a modification (fig 1 ) of one previously used by one of the investigators (NB) in a field trial in northwest Greenland. ${ }^{9}$ The modifications were as follows: ( $a$ ) the base of the coordinometer was enlarged to allow the rheumatoid hand a better grip and $(b)$ the beads were sandblasted to allow a better grip when lifting them out of the bowl. Pilot studies with this instrument suggested that a learning effect occurred in the first $\mathbf{4 8}$ hours, and that 25 beads produced satisfactory data without tiring the patient (cf 50 beads). Subjects were further instructed to complete the questionnaire and BIC at or near the time points indicated, and, in any event, record accurately the actual clock time at which the observation was made. Subjects waking up after 1000 or going to bed before 2200 had less than the six designated observation points a day, but all data recorded were referenced to real time.

Chronograms were constructed for each raw data series in order to view the data for patterns, trends, and outliers. Individual data series were first converted to a percentage of the mean value before constructing overall waveforms for circadian frequencies for the two groups and three variables of interest. ${ }^{7} \mathrm{~A}$ one way analysis of variance (ANOVA) was used to test for the effect of time. In addition, each individual time series was analysed for circadian (about 24 hours) variation using the cosinor techniquethat is, the least squares fitting of cosines with varying periods between 20 and 28 hours with $0.1 \mathrm{~h}$ between trial periods. Group rhythm characteristics at the $24 \mathrm{~h}$ frequency were summarised by population mean cosinor. ${ }^{8}$ Because our interest was in peak performance we expressed our results using the bathyphase rather than the acrophase-that is, the clock time at which pain and stiffness were least and BIC performance best. Table 1 provides a glossary of the relevant terminology used in chronobiology research. ${ }^{10}$

Table 2 Circadian rhythm parameters for self measured coordinometry in control subjects. (Units=elapsed seconds)

\begin{tabular}{|c|c|c|c|c|c|c|c|c|c|c|c|c|c|}
\hline \multirow{2}{*}{$\begin{array}{l}\text { Control } \\
\text { No }\end{array}$} & \multirow[t]{2}{*}{ Sex } & \multirow[t]{2}{*}{ Age } & \multicolumn{4}{|c|}{ Data summary-data limits } & \multicolumn{4}{|c|}{ Rhythm summary at 2400 hours } & \multicolumn{3}{|c|}{ Best fit (hours) } \\
\hline & & & $n$ & Low & High & $R O C^{*}$ & $p$ & $M^{*}$ & $A^{*}$ & $b \phi^{*}$ & Period & $p$ & $A$ \\
\hline $\begin{array}{l}26 \\
25 \\
22 \\
21 \\
19 \\
24 \\
16 \\
20 \\
15 \\
23 \\
17 \\
18 \\
27 \\
28\end{array}$ & $\begin{array}{l}\mathbf{F} \\
\mathbf{F} \\
\mathbf{F} \\
\mathbf{F} \\
\mathbf{F} \\
\mathbf{F} \\
\mathbf{F} \\
\mathbf{F} \\
\mathbf{F} \\
\mathbf{M} \\
\mathbf{M} \\
\mathbf{M} \\
\mathbf{M} \\
\mathbf{M}\end{array}$ & $\begin{array}{l}34 \\
36 \\
39 \\
48 \\
52 \\
55 \\
56 \\
57 \\
60 \\
34 \\
49 \\
61 \\
67 \\
69\end{array}$ & $\begin{array}{l}34 \\
39 \\
42 \\
40 \\
35 \\
35 \\
42 \\
40 \\
41 \\
41 \\
25 \\
39 \\
33 \\
41\end{array}$ & $\begin{array}{l}32 \\
35 \\
35 \\
39 \\
36 \\
48 \\
39 \\
44 \\
35 \\
30 \\
43 \\
49 \\
50 \\
49\end{array}$ & $\begin{array}{l}40 \\
47 \\
40 \\
57 \\
48 \\
63 \\
55 \\
75 \\
52 \\
51 \\
62 \\
67 \\
61 \\
66\end{array}$ & $\begin{array}{r}8 \\
12 \\
5 \\
18 \\
12 \\
15 \\
16 \\
31 \\
17 \\
21 \\
19 \\
18 \\
11 \\
17\end{array}$ & $\begin{array}{r}0.002 \\
0.211 \\
<0.001 \\
0.288 \\
0.006 \\
0.031 \\
0.510 \\
0.006 \\
0.155 \\
<0.001 \\
0.104 \\
<0.001 \\
0.005 \\
0.881\end{array}$ & $\begin{array}{l}36 \cdot 3 \\
39 \cdot 9 \\
36 \cdot 6 \\
47 \cdot 0 \\
42 \cdot 8 \\
58 \cdot 0 \\
46 \cdot 4 \\
56 \cdot 9 \\
44 \cdot 9 \\
38 \cdot 4 \\
53 \cdot 9 \\
56 \cdot 4 \\
53 \cdot 4 \\
56 \cdot 2\end{array}$ & $\begin{array}{l}01 \cdot 8 \\
01 \cdot 4 \\
00 \cdot 9 \\
01 \cdot 4 \\
03 \cdot 5 \\
02 \cdot 7 \\
01 \cdot 2 \\
05 \cdot 7 \\
02 \cdot 1 \\
06 \cdot 1 \\
04 \cdot 2 \\
04 \cdot 9 \\
02 \cdot 6 \\
00 \cdot 5\end{array}$ & $\begin{array}{l}1326 \\
1739 \\
1707 \\
1758 \\
1452 \\
1134 \\
1549 \\
1549 \\
1502 \\
1537 \\
1401 \\
1742 \\
1547 \\
1231\end{array}$ & $\begin{array}{l}23 \cdot 6 \\
24 \cdot 5 \\
24 \cdot 3 \\
27 \cdot 9 \\
24 \cdot 3 \\
24 \cdot 0 \\
25 \cdot 5 \\
24 \cdot 0 \\
23 \cdot 0 \\
23 \cdot 9 \\
23 \cdot 9 \\
23 \cdot 9 \\
24 \cdot 0 \\
27 \cdot 2\end{array}$ & $\begin{array}{r}<0.001 \\
0.169 \\
<0.001 \\
0.230 \\
0.004 \\
0.031 \\
0.211 \\
0.006 \\
0.052 \\
<0.001 \\
0.104 \\
<0.001 \\
0.005 \\
0.023\end{array}$ & $\begin{array}{l}01 \cdot 9 \\
01 \cdot 5 \\
00.9 \\
01 \cdot 6 \\
03.6 \\
02 \cdot 7 \\
01.6 \\
05 \cdot 7 \\
02.3 \\
06 \cdot 1 \\
04 \cdot 2 \\
04.8 \\
02.6 \\
02.7\end{array}$ \\
\hline $\begin{array}{l}\text { Mean } \\
\text { SE }\end{array}$ & & & & & & $\begin{array}{r}16 \\
2\end{array}$ & & $\begin{array}{l}47 \cdot 6 \\
02 \cdot 2\end{array}$ & $\begin{array}{l}02 \cdot 8 \\
00.5\end{array}$ & & $\begin{array}{l}24 \cdot 6 \\
00 \cdot 4\end{array}$ & & $\begin{array}{l}03.0 \\
00.4\end{array}$ \\
\hline
\end{tabular}

${ }^{*} \mathrm{ROC}=$ range of change from lowest to highest value; $M=$ mesor; $A=$ amplitude; $b \phi=b a t h y p h a s e$. 
Table 3 Circadian rhythm parameters for self measured coordinometry in patients with rheumatoid arthritis. (Units=elapsed seconds)

\begin{tabular}{|c|c|c|c|c|c|c|c|c|c|c|c|c|c|}
\hline \multirow{2}{*}{$\begin{array}{l}\text { Patient } \\
\text { No }\end{array}$} & \multirow[t]{2}{*}{$\operatorname{Sex}$} & \multirow[t]{2}{*}{ Age } & \multicolumn{4}{|c|}{ Data summary-data limits } & \multicolumn{4}{|c|}{ Rhythm summary at 2400 hours } & \multicolumn{3}{|c|}{ Best fit (hours) } \\
\hline & & & $n$ & Low & High & $R O C^{*}$ & $p$ & $M^{*}$ & $A^{*}$ & $b \phi^{*}$ & Period & $p$ & $A$ \\
\hline $\begin{array}{l}08 \\
10 \\
12 \\
13 \\
03 \\
07 \\
04 \\
09 \\
02 \\
14 \\
06 \\
01 \\
11 \\
05\end{array}$ & $\begin{array}{l}\mathbf{F} \\
\mathbf{F} \\
\mathbf{F} \\
\mathbf{F} \\
\mathbf{F} \\
\mathbf{F} \\
\mathbf{F} \\
\mathbf{F} \\
\mathbf{F} \\
\mathbf{M} \\
\mathbf{M} \\
\mathbf{M} \\
\mathbf{M} \\
\mathbf{M}\end{array}$ & $\begin{array}{l}35 \\
36 \\
39 \\
48 \\
54 \\
54 \\
55 \\
55 \\
65 \\
33 \\
55 \\
60 \\
62 \\
64\end{array}$ & $\begin{array}{l}40 \\
34 \\
31 \\
37 \\
39 \\
40 \\
35 \\
30 \\
34 \\
27 \\
34 \\
35 \\
40 \\
42\end{array}$ & $\begin{array}{l}42 \\
41 \\
44 \\
45 \\
57 \\
61 \\
40 \\
45 \\
39 \\
50 \\
59 \\
69 \\
50 \\
49\end{array}$ & $\begin{array}{r}59 \\
83 \\
65 \\
57 \\
79 \\
85 \\
61 \\
69 \\
55 \\
81 \\
82 \\
113 \\
80 \\
68\end{array}$ & $\begin{array}{l}17 \\
42 \\
21 \\
12 \\
22 \\
24 \\
21 \\
24 \\
16 \\
31 \\
23 \\
44 \\
30 \\
19\end{array}$ & $\begin{array}{r}0.871 \\
<0.001 \\
0.003 \\
0.512 \\
<0.001 \\
<0.001 \\
0.056 \\
<0.001 \\
0.040 \\
<0.001 \\
0.036 \\
0.033 \\
0.001 \\
<0.001\end{array}$ & $\begin{array}{l}49 \cdot 4 \\
55 \cdot 5 \\
56 \cdot 7 \\
48 \cdot 5 \\
69 \cdot 2 \\
71 \cdot 6 \\
48 \cdot 2 \\
55 \cdot 2 \\
44 \cdot 9 \\
63 \cdot 4 \\
65 \cdot 3 \\
86 \cdot 9 \\
60 \cdot 8 \\
57 \cdot 5\end{array}$ & $\begin{array}{l}00 \cdot 4 \\
09 \cdot 1 \\
04 \cdot 8 \\
00 \cdot 8 \\
05 \cdot 1 \\
06 \cdot 6 \\
03 \cdot 9 \\
08 \cdot 0 \\
03 \cdot 4 \\
08 \cdot 1 \\
04 \cdot 0 \\
07 \cdot 5 \\
06 \cdot 3 \\
05 \cdot 1\end{array}$ & $\begin{array}{l}2212 \\
1549 \\
1654 \\
1944 \\
1338 \\
1617 \\
1444 \\
1622 \\
1648 \\
1621 \\
1343 \\
1259 \\
1606 \\
1613\end{array}$ & $\begin{array}{l}21 \cdot 4 \\
23 \cdot 7 \\
23 \cdot 4 \\
27 \cdot 8 \\
24 \cdot 1 \\
23 \cdot 8 \\
23 \cdot 6 \\
23 \cdot 4 \\
22 \cdot 8 \\
24 \cdot 2 \\
24 \cdot 9 \\
23 \cdot 7 \\
24 \cdot 1 \\
23 \cdot 9\end{array}$ & $\begin{array}{r}0.028 \\
<0.001 \\
0.001 \\
0.132 \\
<0.001 \\
<0.001 \\
0.040 \\
<0.001 \\
0.003 \\
<0.001 \\
0.008 \\
0.029 \\
0.001 \\
<0.001\end{array}$ & $\begin{array}{l}02 \cdot 2 \\
09 \cdot 2 \\
05 \cdot 0 \\
01 \cdot 4 \\
05 \cdot 1 \\
06 \cdot 6 \\
03 \cdot 9 \\
07 \cdot 9 \\
03 \cdot 8 \\
08 \cdot 2 \\
04 \cdot 4 \\
07 \cdot 6 \\
06 \cdot 4 \\
05 \cdot 1\end{array}$ \\
\hline $\begin{array}{l}\text { Mean } \\
\text { SE }\end{array}$ & & & & & & $\begin{array}{r}25 \\
2\end{array}$ & & $\begin{array}{l}59.5 \\
03.0\end{array}$ & $\begin{array}{l}05 \cdot 2 \\
00.7\end{array}$ & & $\begin{array}{l}23.9 \\
00 \cdot 4\end{array}$ & & $\begin{array}{l}05 \cdot 5 \\
00.6\end{array}$ \\
\hline
\end{tabular}

${ }^{*} \mathrm{ROC}=$ range of change from lowest to highest value; $M=$ mesor; $A=$ amplitude; $b \phi=b a t h y p h a s e$

\section{Results}

As previously noted, the first two days' data were discarded to avoid any learning effect.

\section{CONTROL SUBJECTS-BIC}

All subjects showed intrasubject variability (range of change (ROC) mean (SE) 16 (2) seconds and ranging from five to 31 seconds) in BIC scores, with individual scores ranging from 30 to 75 seconds (table 2). After conversion of each series to a percentage of the mean a one way ANOVA between timepoints for the group as a whole detected a significant effect of time $(F=23.4, p<0.001)$. Single cosinor analysis showed significant $(p \leqslant 0.05)$ circadian rhythms

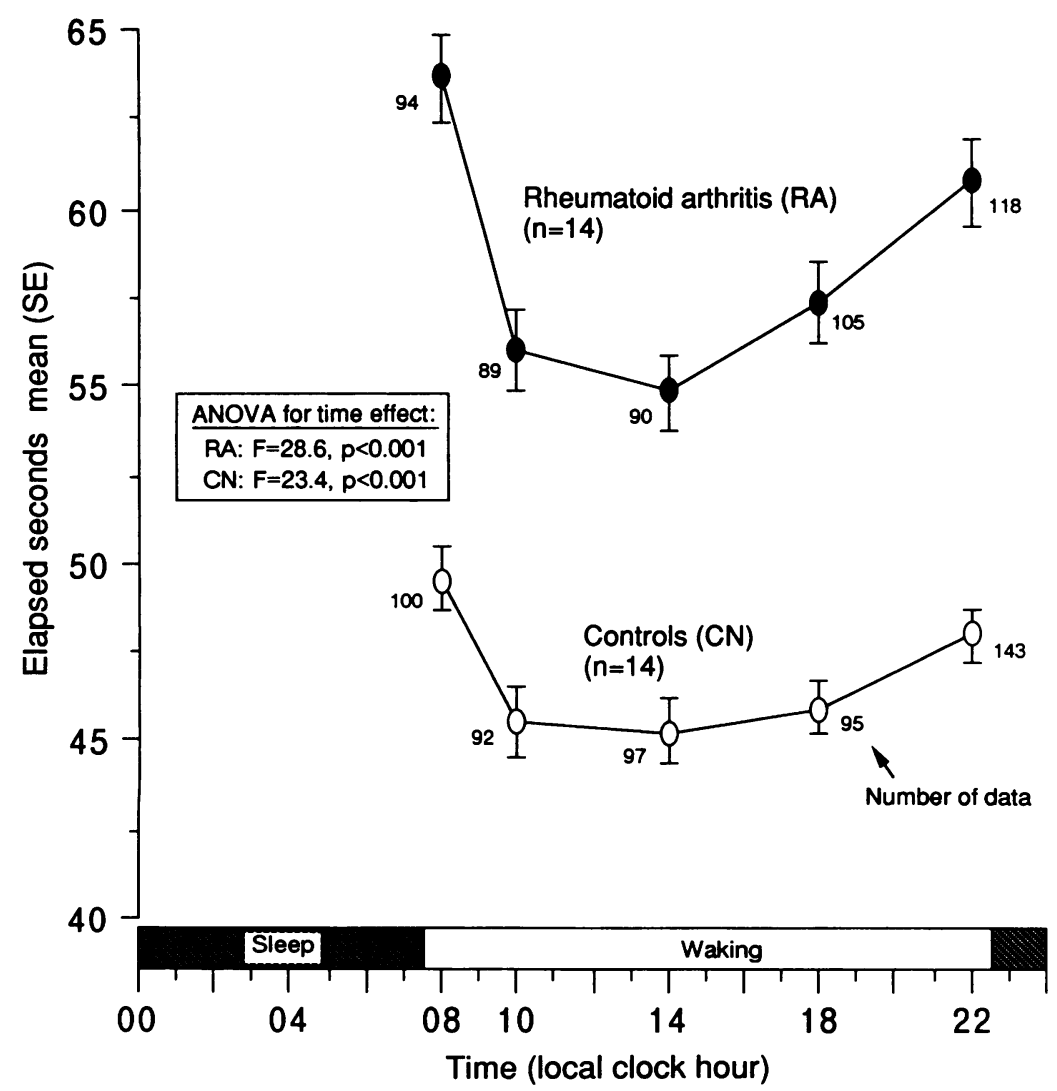

Figure 2 Circadian variation in manual dexterity (measured by bead intubation coordinometry) in patients with rheumatoid arthritis and healthy controls. in the circadian domain for 10 subjects. The location of peak performance (bathyphase, $b \phi$ ) was calculated to be in the afternoon hours with individual $b \phi$ values ranging between 1134 and 1758. Summary by population mean cosinor described a significant circadian rhythm for the group as a whole at $\mathbf{p}=0.001$, with mesor (SE) $47 \cdot 7(2 \cdot 2)$ seconds, amplitude $5 \cdot 4 \%$ (95\% limits $2 \cdot 3,8 \cdot 5)$, and bathyphase at $1528(95 \%$ limits from 1356 to 1648). Thus a circadian rhythm was detected in manual dexterity in subjects clinically free from musculoskeletal and neurological disease.

RA-BIC

As compared with controls, all subjects showed greater intrasubject variability (ROC mean (SE) 25 (2) seconds and ranging from 12 to 44 seconds) in BIC scores, with individual scores ranging from 39 to 113 seconds (table 3 ). Figure 2 shows the timepoint averages for the two groups of subjects. After conversion of each series to a percentage of the mean a one way ANOVA between timepoints for the group as a whole detected a significant effect of time $(\mathrm{F}=28.6, \mathrm{p}<0.001)$. Single cosinor analysis showed significant $(p \leqslant 0.05)$ circadian rhythms in the circadian domain for 13 subjects. The location of the peak performance (bathyphase, b $\phi$ ) was calculated to be in the afternoon to early evening hours with individual $b \phi$ ranging between 1259 and 2212. Summary by population mean cosinor described a significant circadian rhythm for the group as a whole at p $<0.001$, with mesor (SE) 59.5 (3.0) seconds, amplitude $8 \cdot 1 \%(95 \%$ limits $4 \cdot 6,11 \cdot 6)$, and bathyphase at 1544 (95\% limits from 1436 to 1640). Figure 3 shows the temporal relation between peak BIC performance of controls (NCC) and subjects with RA (RAC). This figure displays a vector, whose length represents. the amplitude, pointing in the direction of the bathyphase. The ellipse represents the joint 95\% confidence region within which the true amplitude and bathyphase lie.

RA-PAIN

Data on pain were obtained for only 13 of the 14 
Figure 3 Cosine vector analysis of circadian rhythms in bead intubation coordinometry showing bathyphases in patients with rheumatoid arthritis $(R A C)$ and normal controls (NCC).

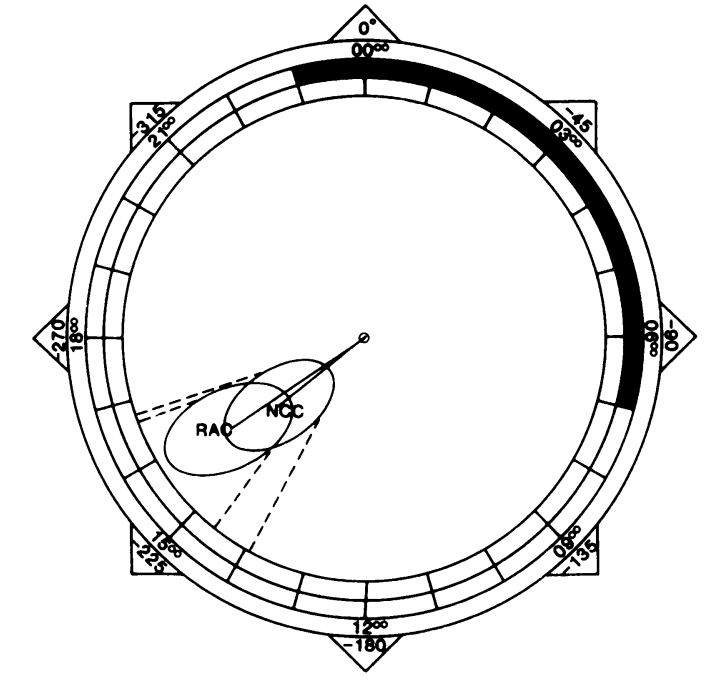

subjects. On a scale of 0 to 100 all subjects showed intrasubject variability (ROC mean (SE) 31 (6) units and ranging from seven to 65) in pain ratings, with individual scores ranging from 0 to 82 units (table 4). After conversion of each series to a percentage of the mean a one way ANOVA between timepoints for the group as a whole detected a significant effect of time $(\mathrm{F}=8.6, \mathrm{p}<0.001)$. Single cosinor analysis showed significant $(p \leqslant 0.05)$ circadian rhythms in the circadian domain for seven subjects. The location of the least pain (bathyphase, $b \phi$ ) was calculated to be generally in the afternoon and evening hours. Summary by population mean cosinor described a significant circadian rhythm for the group as a whole at $p=0.003$, with mesor (SE) $13.4(4.0)$ units, amplitude $49.8 \%$ $(95 \%$ limits $17 \cdot 9,82 \cdot 8)$, and bathyphase at 1700 (95\% limits from 1416 to 1852 ).

RA-STIFFNESS

On a scale of 0 to 100 all subjects showed intrasubject variability (ROC mean (SE) 36 (6) units and ranging from seven to 76) in stiffness ratings, with individual scores ranging from 0 to 82 units (table 4). After conversion of each series to a percentage of the mean a one-way ANOVA between timepoints for the group as a whole detected a significant effect of time $(F=15.6, p<0.001)$. Single cosinor analysis showed significant $(p \leqslant 0.05)$ circadian rhythms in the circadian domain for 11 subjects. The location of the least stiffness (bathyphase, $b \phi$ ) was calculated to be generally in the afternoon and evening hours. Summary by population mean cosinor described a significant circadian rhythm for the group as a whole at $\mathrm{p}=0.020$, with mesor (SE) 18.3 (3.4) units, amplitude $33 \cdot 2 \%(95 \%$ limits $5 \cdot 2,61 \cdot 5)$, and bathyphase at 1724 (95\% limits from 1352 to 1944). Figure 4 shows the timepoint averages for pain (RAP) and stiffness (RAS) ratings and manual dexterity (RAC) for patients with RA, and fig 5 shows the circadian timing of these variables. A temporal relation between manual dexterity and ratings of pain and stiffness was thus established in patients with rheumatoid arthritis.

\section{Discussion}

Pain, stiffness, and physical function are key outcome measures in RA clinical trials, their importance being emphasised by their inclusion in the guidelines of several agencies, including the European League Against Rheumatism ${ }^{11}$ and the Food and Drug Administration, ${ }^{12}$ and by the frequency with which they have been used in antirheumatic drug trials. ${ }^{13}$ In this study we used conventional $10 \mathrm{~cm}$ visual analogue scales and a novel instrument (BIC) not previously used in the assessment of patients with RA. Performance of BIC may be altered by the presence of musculoskeletal or neurological disease. The patients in this study had no clinical evidence of neurological disease, and thus differences between patients and controls were due to the presence of articular disease. As such, the BIC test became a measure of dominant limb manual dexterity.

In this study we mapped daily changes in pain, stiffness, and BIC in a group of patients with RA who are typical of those recruited for non-steroidal anti-inflammatory drug studies. It is of note that variability in most, but not all,

Table 4 Circadian rhythm parameters for self measured pain and stiffness in patients with rheumatoid arthritis. Values are given as rating on a scale from 0 to 100

\begin{tabular}{|c|c|c|c|c|c|c|c|c|c|c|c|c|c|c|c|c|c|c|c|c|c|c|}
\hline \multirow{3}{*}{$\begin{array}{l}\text { Patient } \\
\text { No }\end{array}$} & \multicolumn{11}{|c|}{ Pain rating } & \multicolumn{11}{|c|}{ Stiffness rating } \\
\hline & \multicolumn{4}{|c|}{$\begin{array}{l}\text { Data summary-data } \\
\text { limits }\end{array}$} & \multicolumn{4}{|c|}{$\begin{array}{l}\text { Rhythm summary-at } \\
2400 \text { hours }\end{array}$} & \multicolumn{3}{|c|}{ Best fit (hours) } & \multicolumn{4}{|c|}{$\begin{array}{l}\text { Data summary-data } \\
\text { limits }\end{array}$} & \multicolumn{4}{|c|}{$\begin{array}{l}\text { Rhythm summary -at } \\
2400 \text { hours }\end{array}$} & \multicolumn{3}{|c|}{ Best fit (hours) } \\
\hline & $n$ & Low & High & $R O C^{*}$ & $p$ & $M^{*}$ & $A^{*}$ & $\boldsymbol{B} \phi^{*}$ & Period & $p$ & $A$ & $n$ & Low & High & $R O C^{*}$ & $p$ & $M^{*}$ & $A^{*}$ & $B \phi^{*}$ & Period & $p$ & $A$ \\
\hline $\begin{array}{l}08 \\
10 \\
12 \\
13 \\
03 \\
07 \\
04 \\
09 \\
02 \\
14 \\
06 \\
01 \\
11 \\
05\end{array}$ & $\begin{array}{r}0 \\
34 \\
30 \\
37 \\
38 \\
39 \\
35 \\
30 \\
34 \\
27 \\
34 \\
34 \\
40 \\
42\end{array}$ & $\begin{array}{r}-9 \\
0 \\
7 \\
4 \\
6 \\
0 \\
18 \\
0 \\
2 \\
0 \\
3 \\
2 \\
1\end{array}$ & $\begin{array}{l}73 \\
18 \\
15 \\
69 \\
48 \\
24 \\
82 \\
7 \\
13 \\
13 \\
30 \\
35 \\
24\end{array}$ & $\begin{array}{r}\overline{6} \\
64 \\
18 \\
8 \\
65 \\
42 \\
24 \\
64 \\
7 \\
11 \\
13 \\
27 \\
33 \\
23\end{array}$ & $\begin{array}{r}- \\
<0.001 \\
0.352 \\
0.181 \\
0.003 \\
0.043 \\
0.205 \\
<0.001 \\
0.004 \\
0.012 \\
0.074 \\
0.155 \\
0.003 \\
0.146\end{array}$ & $\begin{array}{l}\overline{32} \cdot 2 \\
04 \cdot 3 \\
09 \cdot 8 \\
35 \cdot 2 \\
13 \cdot 6 \\
02 \cdot 0 \\
45 \cdot 3 \\
01 \cdot 5 \\
06 \cdot 0 \\
01 \cdot 1 \\
08 \cdot 3 \\
08 \cdot 8 \\
06 \cdot 4\end{array}$ & $\begin{array}{l}\overline{17} \cdot 9 \\
02 \cdot 5 \\
00 \cdot 9 \\
17 \cdot 0 \\
03 \cdot 9 \\
02 \cdot 0 \\
28 \cdot 1 \\
02 \cdot 0 \\
02 \cdot 1 \\
01 \cdot 6 \\
02 \cdot 6 \\
05 \cdot 0 \\
02 \cdot 5\end{array}$ & $\begin{array}{l}\overline{1604} \\
1710 \\
0551 \\
1701 \\
1835 \\
1254 \\
1737 \\
1832 \\
1831 \\
1722 \\
2137 \\
1849 \\
1504\end{array}$ & $\begin{array}{l}\overline{24} \cdot 2 \\
21 \cdot 0 \\
24 \cdot 5 \\
24 \cdot 5 \\
24 \cdot 0 \\
24 \cdot 6 \\
24 \cdot 1 \\
23 \cdot 4 \\
24 \cdot 4 \\
23 \cdot 8 \\
24 \cdot 8 \\
24 \cdot 2 \\
24 \cdot 8\end{array}$ & $\begin{array}{r}- \\
<0.001 \\
0.217 \\
0.144 \\
<0.001 \\
0.043 \\
0.181 \\
<0.001 \\
0.002 \\
0.011 \\
0.070 \\
0.134 \\
0.003 \\
0.059\end{array}$ & $\begin{array}{l}\overline{18} \cdot 1 \\
02 \cdot 6 \\
01 \cdot 0 \\
18 \cdot 8 \\
03 \cdot 9 \\
02 \cdot 1 \\
28 \cdot 2 \\
02 \cdot 1 \\
02 \cdot 2 \\
01 \cdot 7 \\
02 \cdot 9 \\
05 \cdot 0 \\
02 \cdot 9\end{array}$ & $\begin{array}{l}40 \\
34 \\
30 \\
37 \\
39 \\
39 \\
35 \\
30 \\
34 \\
27 \\
34 \\
34 \\
40 \\
42\end{array}$ & $\begin{array}{r}0 \\
7 \\
0 \\
8 \\
9 \\
15 \\
1 \\
6 \\
0 \\
3 \\
0 \\
10 \\
9 \\
1\end{array}$ & $\begin{array}{r}7 \\
75 \\
40 \\
17 \\
72 \\
54 \\
36 \\
82 \\
9 \\
26 \\
19 \\
60 \\
50 \\
29\end{array}$ & $\begin{array}{r}7 \\
68 \\
40 \\
9 \\
63 \\
39 \\
35 \\
76 \\
9 \\
23 \\
19 \\
50 \\
41 \\
28\end{array}$ & $\begin{array}{r}0.481 \\
<0.001 \\
0.217 \\
0.169 \\
<0.001 \\
<0.001 \\
0.300 \\
<0.001 \\
<0.001 \\
<0.001 \\
0.632 \\
0.015 \\
0.002 \\
0.262\end{array}$ & $\begin{array}{l}01 \cdot 7 \\
34 \cdot 6 \\
17 \cdot 4 \\
11 \cdot 6 \\
39 \cdot 7 \\
29 \cdot 5 \\
06 \cdot 4 \\
35 \cdot 5 \\
02 \cdot 6 \\
12 \cdot 8 \\
09 \cdot 4 \\
26 \cdot 0 \\
21 \cdot 2 \\
07 \cdot 5\end{array}$ & $\begin{array}{l}00 \cdot 5 \\
20 \cdot 5 \\
05 \cdot 4 \\
01 \cdot 3 \\
19 \cdot 6 \\
08 \cdot 7 \\
02 \cdot 6 \\
37 \cdot 4 \\
02 \cdot 7 \\
06 \cdot 5 \\
01 \cdot 7 \\
07 \cdot 9 \\
07 \cdot 1 \\
02 \cdot 9\end{array}$ & $\begin{array}{l}0703 \\
1600 \\
1726 \\
0223 \\
1615 \\
1702 \\
1259 \\
1656 \\
1918 \\
1819 \\
0306 \\
2036 \\
1825 \\
1544\end{array}$ & $\begin{array}{l}26 \cdot 2 \\
24 \cdot 1 \\
22 \cdot 5 \\
21 \cdot 8 \\
24 \cdot 6 \\
23 \cdot 7 \\
24 \cdot 7 \\
24 \cdot 1 \\
22 \cdot 9 \\
24 \cdot 5 \\
20 \cdot 0 \\
23 \cdot 8 \\
24 \cdot 0 \\
25 \cdot 6\end{array}$ & $\begin{array}{r}0.021 \\
<0.001 \\
0.026 \\
0.120 \\
<0.001 \\
<0.001 \\
0.236 \\
<0.001 \\
<0.001 \\
<0.001 \\
0.222 \\
0.014 \\
0.002 \\
0.032\end{array}$ & $\begin{array}{l}01 \cdot 1 \\
20 \cdot 6 \\
07 \cdot 5 \\
01 \cdot 3 \\
21 \cdot 4 \\
08 \cdot 7 \\
02.9 \\
37 \cdot 6 \\
03.0 \\
06.9 \\
02 \cdot 2 \\
08 \cdot 0 \\
07 \cdot 1 \\
03 \cdot 7\end{array}$ \\
\hline $\begin{array}{l}\text { Mean } \\
\text { SE }\end{array}$ & & & & $\begin{array}{r}31 \\
6\end{array}$ & & $\begin{array}{l}13 \cdot 4 \\
04.0\end{array}$ & $\begin{array}{l}06 \cdot 8 \\
02 \cdot 4\end{array}$ & & $\begin{array}{l}24 \cdot 0 \\
00 \cdot 3\end{array}$ & & $\begin{array}{l}07 \cdot 0 \\
02 \cdot 4\end{array}$ & & & & $\begin{array}{r}36 \\
6\end{array}$ & & $\begin{array}{l}18 \cdot 3 \\
03 \cdot 4\end{array}$ & $\begin{array}{l}08 \cdot 9 \\
02 \cdot 8\end{array}$ & & $\begin{array}{l}23 \cdot 8 \\
00 \cdot 4\end{array}$ & & $\begin{array}{l}09 \cdot 4 \\
02 \cdot 8\end{array}$ \\
\hline
\end{tabular}




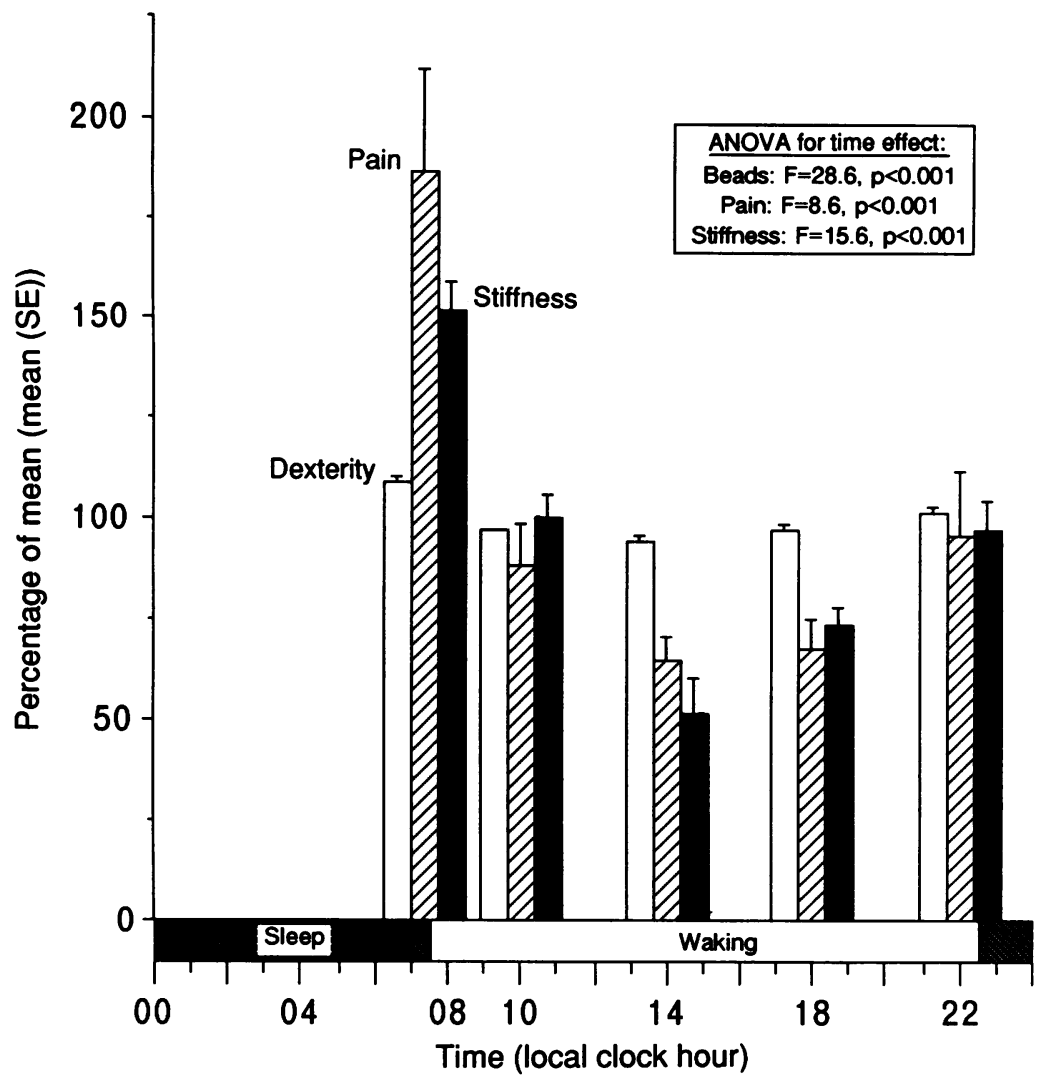

Figure 4 Circadian variation in pain, stiffness, and manual dexterity (measured by bead intubation coordinometry) in 14 patients with rheumatoid arthritis.

Figure 5 Cosine vector analysis of circadian rhythms in pain $(R A P)$, stiffness (RAS), and bead intubation coordinometry ( $R A C$ ) showing bathyphases in rheumatoid arthritis.

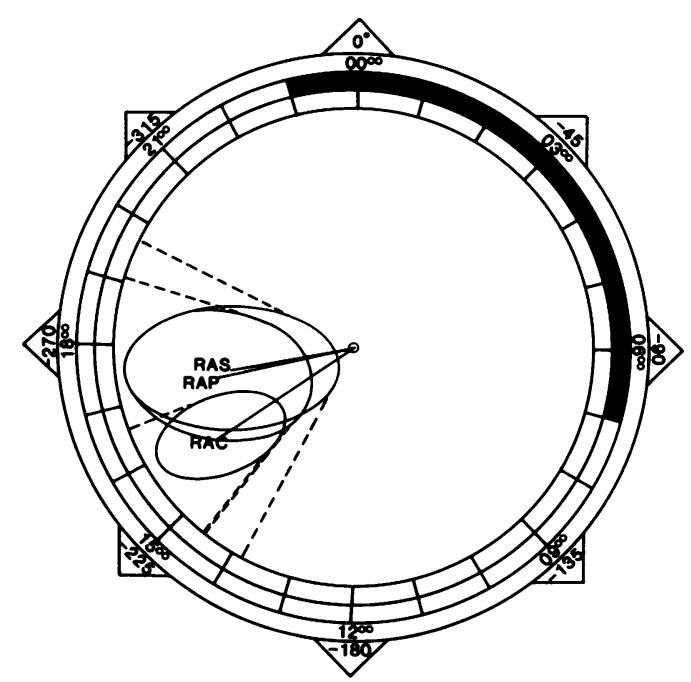

patients with RA was not random but showed a statistically significant adherence to a quasisinusoidal rhythm having a period of about 24 hours. The data suggest that the level of pain, stiffness, and BIC performance throughout the day are in part predictable. Furthermore, we noted that BIC performance is best about the time that pain and stiffness are least-that is, in the late afternoon or early evening. Indeed, it would be expected that performance-that is, dexterity-would improve as joint stiffness lessened. BIC, therefore, may be a potential surrogate measure for stiffness, though current data do not allow this contention to be substantiated. Analgesic counts were not followed in this study, neither were Environment Canada statistics on temperature and humidity obtained. We believe that the cause of circadian variation cannot be fully dissected without such information. In a previous study of circadian and circaseptan rhythms in pain perception in osteoarthritis we were unable to show any significant relation between fluctuations in pain scores and either analgesic consumption or biometeorological factors. ${ }^{14}$ Indeed, a circadian rhythm in analgesic consumption might be expected as a response to the circadian rhythm in pain. The lack of such a rhythm may be due to a number of factors, including erratic reporting, subject variability in pain threshold, or the occurrence of high amplitude but low level rhythms of pain. Although the lack of analgesic data restricts the conclusions which can be drawn from this study, it should be noted that supplementary analgesic consumption is often permitted in clinical trials, and that in this study any confounding effects on pain, stiffness, and BIC would be concurrent. We feel, therefore, that our study replicates clinical trial conditions. Our data have obvious implications for the use of pain and stiffness scales and BIC in clinical trials. In particular, they indicate that the time of use should be kept constant, and certainly, because the variability we noted was nonrandom in most patients variation of any patient's assessment time between morning and afternoon during the course of a trial should be avoided.

The circadian rhythmicity in BIC in healthy normal controls found in this study differs from that previously noted in 12 medical students in northwest Greenland. ${ }^{9}$ In that study no statistically significant rhythm was detected in BIC, but the field conditions were severe: low ambient temperature, dry skin, and the polished surface of the beads contributing to the difficulty of performing the task. We believe that sandblasting the beads was a major contribution to our success in detecting rhythmicity in this study. It is of note that the BIC performance of healthy controls was characterised by a rhythm of lower level and smaller amplitude than in patients with RA. The lower level is accounted for by the faster speed at which healthy subjects completed the tasks. The smaller amplitude is probably due to the absence of the modulating influences of pain, stiffness, and other aspects of the inflammatory process which may make it more difficult to perform BIC at some times of day than others. In contrast, it is of interest to note that peak BIC performance (as defined by the bathyphase) in patients with $R A$ and controls occurred at almost exactly the same time. This may indicate that the performance profile of patients with RA merely represents a vertical distortion of the normal rhythm found in healthy controls. This distortion may be mediated by the modulating influences of joint pain and stiffness, though this contention cannot be substantiated from the current data.

In a separate study (unpublished data) we demonstrated the responsiveness $(p=0.02)$ of $B I C$ performance in 21 patients with $R A$ receiving flurbiprofen after a washout period free from non-steroidal anti-inflammatory drugs. When taken together with the present data 
on between-subject and within-subject variability-that is, reliability-and given the instrument's face and discriminant validitythat is, RA $v$ controls-we believe that BIC may usefully complement grip strength and arthrocircometry as an objective measure of disease activity in RA clinical trials. Finally, this study has shown that least squares and cosine vector techniques, which are traditional methods of anlaysis in the discipline of chronobiology, may be applicable in dissecting the time structure of the musculoskeletal diseases.

1 Kowanko I C, Pownall R, Knapp M S, Swannell A J Mahoney P G C. Circadian variations in the signs and Mymptoms of rheumatoid arthritis and in the therapeutic symptoms of rheumatoid arthritis and in the therapeutic
effectiveness of flurbiprofen at different times of day. $\mathrm{Br} \mathcal{F}$ Clin Pharmacol 1981; 11: 477-84.

2 Harkness J A L, Richter M B, Panayi G S, et al. Circadian variation in disease activity in rheumatoid arthritis. $B M \mathcal{J}$ 1982; 284: 551-4.

3 Kowanko I C, Knapp M S, Pownall R, Swannell A J. Domiciliary self-measurement in rheumatoid arthritis and the demonstration of circadian rhythmicity. Ann Rheum Dis 1982; 41: 453-5.

4 Sitton N G, Taggart A J, Dixon J S, Surrall K E, Bird H A. Circadian variation in biochemical assessments used to monitor rheumatoid arthritis. Ann Rheum Dis 1984; 43: 444-50.

5 Brothers Jr G B, Hadler N M. Diurnal variations in rheumatoid synovial effusions. I Rheumatol 1983; 10: $471-4$.

6 Petersen I, Baatrup G, Brandslund I, Teisner B, Rasmussen G G, Svehag S-E. Circadian and diurnal variation of circulating immune complexes, complement-mediated solubilization, and the complement split product C3d in

rheumatoid arthritis. Scand $\mathcal{F}$ Rheumatol 1986; 15: 113-8.
Halberg F, Johnson E A, Nelson W, Runge W, Sothern Halberg F, Johnson E A, Nelson W, Runge W, Sothern
R. Autorhythmometry-procedures for physiologic selfmeasurement and their analysis. Physiology Teacher 1972; 1: $1-11$.

8 Nelson W, Tong Y L, Lee J K, Halberg F. Methods for cosinor-rhythmometry. Chronobiologia 1979; 6: 305-23.

9 Simpson $H$ W, Bellamy N, Bohlen J, Halberg F. Double blind trial of a possible chronobiotic (Quiadon) ${ }^{\mathrm{R}}$; field studies in N.W. Greenland. International fournal of Chronobiology 1973; 1: 287-311.

10 Halberg F, Carandente G, Corneilissen G, Katinas G. Glossary of chronobiology. Chronobiologia 1977; 4 (suppl 1): 1-189.

11 World Health Organisation. Guidelines for the clinical investigation of drugs used in rheumatic diseases. Basle: European gation of drugs used in rheumatic diseases. Bas
League Against Rheumatism, 1985: 7-11.

12 US Department of Health and Human Services, Food and Drug Administration, Guidelines for the clinical evaluation of anti-inflammatory and anti-rheumatic drugs (adults and children). USA: FDA, 1988: 33-5.

13 Bellamy N, Buchanan W W. Clinical evaluation in rheumatic diseases. In: McCarty D J, ed. Arthritis and allied conditions. 11th ed. Philadelphia: Lea and Febiger, 1989: 158-86.

14 Bellamy N, Sothern R B, Campbell J. Rhythmic variations in pain perception in osteoarthritis of the knee. $\mathcal{F}$ Rheumatol 1990; 17: 364-72. 